\title{
THE RELATIONSHIP BETWEEN ORGANIZATIONAL SPACE OF OFFICES AND CORPORATE IDENTITY (CASE STUDY: GENERAL OFFICES IN AZERBAIJAN)
}

\author{
Mehran Moulavi ${ }^{1}$, Parivash Mohammadi ${ }^{2},{\text { Hassan } \text { Zirak }^{3} \text { and Fariba Azizzadeh }}^{4}$ \\ 1 \& 2 Islamic Azad University, Department of Management, Mahabad, Iran \\ ${ }^{3}$ M.A of Public Administration, Islamic Azad University, Department of Management, \\ Mahabad, Iran \\ ${ }^{4}$ Islamic Azad University, Department of Management, Science and Research Branch, \\ Isfahan, Iran (Corresponding author)
}

\begin{abstract}
Institutional space as the value system determines what methods work and what behaviors are approved. This study aimed to identify the relationship between organizational space (organizational structure, corporate responsibility, corporate support and productivity management) with senior administration identity of corporate managers of West Azerbaijan. 150 standardized questionnaires were distributed among population and 100 questionnaires were returned to test hypotheses. According to normal data, the Pearson correlation coefficient used to determine the type and extent of the relationship between the variables. The results show there is a direct relationship between corporate responsibility, productivity management, organizational support and corporate identity. However, a significant relationship between the dimensions of organizational structure and corporate identity does not exist. So we suggest that serious efforts should be made in General Offices in West Azerbaijan by exercising efficiently management and developing appropriate organizational space (with respect to the liability of agents, productivity management and organizational support) in order to improve organizational identity administration.
\end{abstract}

\section{KEYWORDS}

Organizational Space, Organizational Structure, Corporate Responsibility, Corporate Identity, Corporate Support

\section{INTRODUCTION}

No doubt today's world is the world of humans and custodians of human organizations. Without human organizations, not only would it mean it would not be possible to run them. The social life of mankind requires cooperation, collaboration and mutual needs. These led to division of labor and the development of skills and expertise and are added to the development of quantitative and qualitative effects and the results. 
Institutional space refers to a set of property substantial size making in the workplace. This property, directly or indirectly, will be affect by the people who live and work in that environment, perception and motivation and their behavior. In fact, institutional environment is the atmosphere in which people pay for their work, so this space can affect motivation, performance and job satisfaction. Four dimensions of organizational climate are organizational structure, management efficiency, accountability, and support organizations. This study examined the relationship between these four dimensions with organizational identity.

Corporate identity means the individual feeling attachment to the company and being a valued member of a working group. In corporate responsibility people feel they are in charge, not all of their decisions should be reviewed by supervisors. There is assistance and cooperation feeling between managers and staff supported and emphasize the face in organizational support .In this study, the organizational structure means the employees feel about organizational pressure, legislation, line meshes, administrative procedures and regulations. Productivity is defined as maximizing the use of resources, manpower and through scientific measures to reduce costs and employee satisfaction, managers and consumers. The organizations need programming and tools to increase the motivation of their employees which this study determines whether there is a gap between organizational space and identity in West Azerbaijan General Offices or not.

\section{LITERATURE REVIEW}

The organizational productivity increase when the organizational culture enterprise purpose to organizational priorities and sometimes changes shape. Studies show that organizational culture is a key factor for improving the performance of productivity and organization plays a vital role in the success or failure (Kazemi, 2010). Productivity and organizational culture are closely related to each other (Kashani and Khanyfar, 2011).

According to French (1986), based on existing theories and studies, the best organizational space cannot be introduced. Litwin and Stringer (1986) and colleagues in this regard say that it is meaningless to tell managers how to manage. The Manager determines the space which requires high performance.

Organizational space has a major role in the organization (Boulden, 1992). Litwin and Stringer (1968) also after doing lots of research argue that leadership style is an important factor that affects the organizational space. They suggest that organizational space refers to the perceptions of members of the formal system, the informal methods of management and also other environmental important factors. In this perception, attitudes, beliefs, values and motivations particularly affects people in a work environment. So the following nine-part indicator has identified for organizational areas:

1. Organizational structure: employees feel about stress, organizational climate, laws, policies, procedures, regulations and administrative.

2. Responsibility: people feel responsible for their own decisions, they're not all be reviewed by the supervisors.

3. Bonus: people feel about rewarding of good practice, pay equity, and prosperity policies.

4. Risk: feel challenged at work and in the organization, is it encouraged by the risks account or safest way to do? 
5. Friendship: Feel the love and kindness in the workplace and expanding informal and friendly group.

6. Support: Feel the assistance and cooperation between managers and employees emphasizing support.

7. Criteria: Count of targets and performance measures, emphasis on doing the right job, the challenges of individual and group goals.

8. Conflict: managers and employees tend to listen to opposing opinions and theories, the emphasis on conflict resolution instead of turning off or ignoring them.

9. Identity: An individual's sense of attachment to the company and a valuable member of a working group.

French (1986) argues that organizational survival depends on managers due to external environmental factors, internal environmental and output (result). These factors are influenced by each other. For example, remote management by supporting educational programs (internal factors) influences on employment legal issues (which is an external factor). Taheri (2006), in his book highlights several cases such as the concept of productivity, the necessity of comprehensive utilization management, utilization management concept and philosophy encompassing new ideas, measuring productivity and improve efficiency, the most important factor affecting the productivity such as labor, management indicators, productivity management inclusive principles and benefits and comprehensive productivity management model.

\section{RESEARCH METHOD}

This research is applied research. It is also a correlation research. This research also is considered to be descriptive in terms of data gathering (research project). In general it can be said that the research methods is descriptive - survey and correlation. In this study, all organizational managers are used to achieve the research objectives and the population is selected from administrations of West Azerbaijan. Since statistical societies usually have a lot of volume, and geographic extent and cannot go to all of them, we are forced to choose some examples and generalize the results to the research community (Farhangi \& Safarzadeh, 2008, pp. 243). Due to the protective reasons, there was not access to the membership population base and central administration of West Azerbaijan managers. We estimated the sample size according to the following formula.

$$
n=\frac{z_{\alpha}^{2} \times \mathrm{S}^{2}}{\mathrm{~d}^{2}}
$$

The most important parameter is $S^{2}$ that this formula requires the variance first sample. 25 questionnaires were distributed between the prototype to calculate $\mathrm{S}^{2}$ and its variance was calculated and its value is equal to 0.0729 . In this study, the error level of is assumed as $5 \%$, so the confidence level would be $95 \%$. So $\mathrm{z}(\alpha / 2)$ given by Table 1.96, and the value of $\mathrm{d}$ equal to 0.05 was considered on the same level of error.

So according to the numeric value that is obtained from the formula, the sample size would be 100 , but 150 questionnaires were distributed of which 100 questionnaires were completed. According to the General Offices of Azerbaijan, a major community-based sample of middle and base managers were selected randomly. In this study we have used a standard questionnaire 
consisting of 54 questions, which are in line with the questionnaire designed by Moghimi (2011) and Saatchi et al (2011). The order scale is used due to the qualitative nature of variables of this study.

Questions from 1 till 24 are related with dimensions of organizational structure that include questions about: job titles, level of education, level of management, job description, rules, hierarchy, and etc. Questions of 25 until 30 are related with organizational responsibility and also 31 till 38 are about corporate identity. Questions about organizational support being raised in 39 till 46 and questions of 47 until 54 examine the productivity of managers.

Likert scale was used to determine the variables in each of the five. Accountability measures are enclosed as agreed between the two ultimate limit of love - hate and acceptance - rejection, and based on weakness of attitude. Cronbach's alpha was used to calculate the reliability of the method, which was calculated using SPSS software. To this end, a prototype consisting of 35 questions, including basic and middle managers and departments, have been collected. Using data obtained from the questionnaire and analyzed using SPSS statistical software reliability coefficient was calculated by using Cronbach's alpha than was calculated as 0.88 . Based on the Minimum reliability coefficient for research questionnaires as $0 / 7$ it is to be noted that Cronbach's alpha coefficient obtained is higher than this value. To describe the data, descriptive statistics and inferential statistics were used for data analysis and hypothesis testing. Finally, correlation coefficient was used for analysis and better decision about whether or not there is a significant relationship. Pearson or Spearman correlation will be used to determine the type and extent of relationship between variables according to normal or abnormal data.

The survey data using Excel and SPSS software was performed in two parts of descriptive statistics and inferential statistics used in the analysis. The research model is shown below:

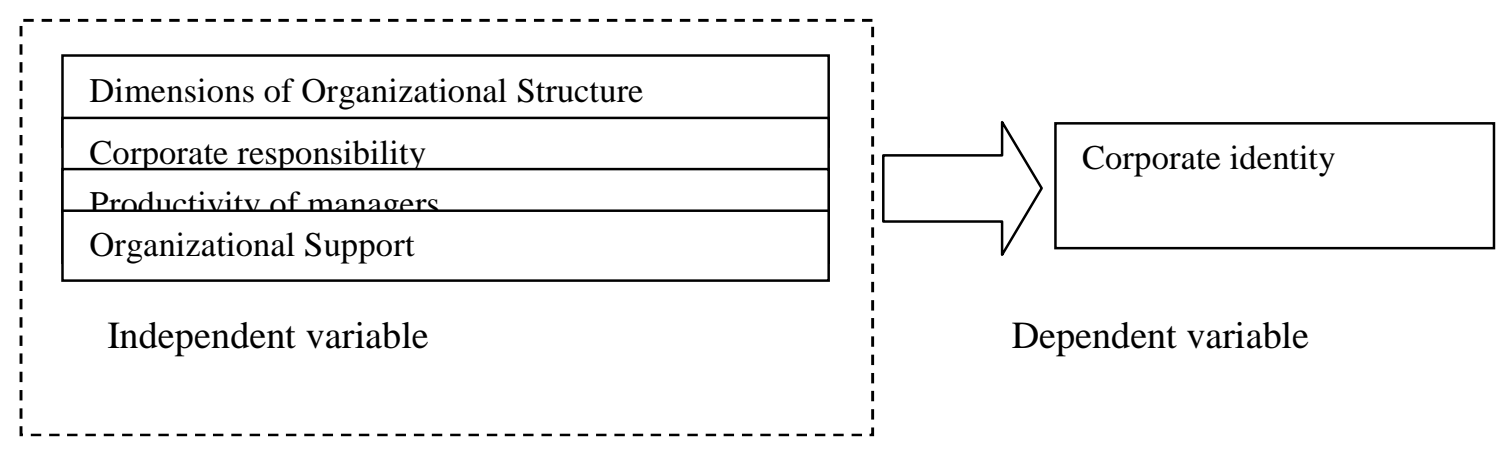

Figure 1. Theoretical model of research

\section{DATA ANALYSIS}

Data normality investigated by using the central limit theorem. Here, based on the central limit theorem and given that the sample size was estimated to be more than 30 people, normality of the data is accepted and parametric methods and Pearson correlation will be used to examine the hypothesis. 


\section{Test Hypotheses}

H0: there is no significant relationship between International dimensions of organizational structure and corporate identity in the administration of West Azerbaijan.

H1: there is a significant relationship between International dimensions of organizational structure and corporate identity in the administration of West Azerbaijan,

In Table 1 , it is seen that the correlation between the variables is 0.119 , which shows almost no correlation. However, since a significant level of correlation (0.237) higher than the coefficient of error (0.01), so the null hypothesis (assuming no relation) is not rejected and therefore we can rule out that there is no significant relationship between the dimensions of organizational structure and corporate identity in the administration of West Azerbaijan.

Table 1. The correlation between the dimensions of organizational structure and corporate identity

\begin{tabular}{|ll|l|l|}
\hline & & $\begin{array}{l}\text { Organizational } \\
\text { structure }\end{array}$ & Corporate identity \\
\hline \multirow{2}{*}{\begin{tabular}{ll|l|} 
Organizational \\
structure
\end{tabular}} & Pearson Correlation & 1 & .119 \\
& Sig. (2-tailed) & & .237 \\
& $\mathrm{~N}$ & 100 & 100 \\
\hline \multirow{3}{*}{ Corporate identity } & Pearson Correlation & .119 & 1 \\
& Sig. (2-tailed) & .237 & \\
& $\mathrm{~N}$ & 100 & 100 \\
\hline
\end{tabular}

H0: there is no significant relationship between corporate responsibility and corporate identity in the administration of West Azerbaijan.

H1: there is a significant relationship between corporate responsibility and corporate identity in the administration of West Azerbaijan.

In Table 2, it is seen that the correlation between the variables is 0.549 , which indicates relatively poor correlation. However, since a significant level of correlation (0.000) is less than the coefficient of error (0.01), so the null hypothesis (assuming no relation) has rejected the hypothesis of a $99 \%$ safety factor accept and there is a significant relationship between the index between corporate responsibility and corporate identity in the administration of West Azerbaijan. 
International Journal of Security, Privacy and Trust Management (IJSPTM) Vol 3, No 1, February 2014

Table 2 . The correlation between the dimensions of corporate responsibility and corporate identity

\begin{tabular}{|ll|l|l|}
\hline & & $\begin{array}{l}\text { corporate } \\
\text { responsibility }\end{array}$ & $\begin{array}{l}\text { corporate } \\
\text { identity }\end{array}$ \\
\hline \multirow{2}{*}{$\begin{array}{lll}\text { corporate } \\
\text { responsibility }\end{array}$} & $\begin{array}{l}\text { Pearson } \\
\text { Correlation }\end{array}$ & 1 & $.549^{* *}$ \\
& $\begin{array}{l}\text { Sig. (2-tailed) } \\
\mathrm{N}\end{array}$ & 100 & $\begin{array}{l}.000 \\
100\end{array}$ \\
\hline & Pearson & $.549^{* *}$ & 1 \\
corporate & Correlation \\
identity & Sig. (2-tailed) & .000 & 100 \\
& $\mathrm{~N}$ & 100 & 100 \\
\hline
\end{tabular}

**. Correlation is significant at the 0.01 level (2-tailed).

H0: there is a significant relationship between the productivity of office managers and corporate identity in Western Azerbaijan province

H1: there is a significant relationship between the productivity of office managers and corporate identity in Western Azerbaijan province.

Table 3 shows the correlation between the amounts of variables equal to 0.623 , which indicates a relatively strong positive correlation. However, since a significant level of correlation (0.000) is less than the coefficient of error (0.01), so we accept a $99 \%$ safety factor of hypothesis and can conclude that there is a significant relationship between the productivity of managers and corporate identity in the administration of West Azerbaijan.

Table 3. The correlation between the dimensions of productivity of office managers and corporate identity

\begin{tabular}{|cl|l|l|}
\hline & $\begin{array}{l}\text { productivity of } \\
\text { office managers }\end{array}$ & corporate identity \\
\hline $\begin{array}{l}\text { Pearson } \\
\text { productivity of Correlation } \\
\text { office managers }\end{array}$ & 1 & $.623^{* *}$ \\
& Sig. (2-tailed) \\
& $\mathrm{N}$ & 100 & .000 \\
& $\begin{array}{c}\text { Pearson } \\
\text { Correlation } \\
\text { Sig. (2-tailed) }\end{array}$ & $.623^{* *}$ & 100 \\
\hline $\mathrm{N}$ & .000 & 1 \\
corporate identity & 100 & 100 \\
\hline
\end{tabular}

**. Correlation is significant at the 0.01 level (2-tailed).

H0: there is no significant relationship between organizational support and corporate identity in the administration of West Azerbaijan, 
H1: there is a significant relationship between organizational Support and Organizational Identity in the administration of West Azerbaijan.

According to SPSS software output in Table 4, it is seen that the correlation between the variables equal to 0.623 , which indicates a relatively strong positive correlation. Since a significant level of correlation (0.000) is less than the coefficient of error (0.01), so we reject the null hypothesis and accept the research hypothesis with a $99 \%$ safety factor and there is a significant relationship between organizational support and corporate identity in the administration of West Azerbaijan.

Table 4. The correlation between the dimensions of organizational support and corporate identity

\begin{tabular}{|c|c|c|c|}
\hline & & \begin{tabular}{|l} 
organizational \\
support
\end{tabular} & \begin{tabular}{|l} 
corporate \\
identity
\end{tabular} \\
\hline \multirow{3}{*}{$\begin{array}{l}\text { organizational } \\
\text { support }\end{array}$} & $\begin{array}{l}\text { Pearson } \\
\text { Correlation }\end{array}$ & 1 & $.623^{* *}$ \\
\hline & Sig. (2-tailed) & & .000 \\
\hline & $\mathrm{N}$ & 100 & 100 \\
\hline \multirow{3}{*}{ corporate identity } & $\begin{array}{l}\text { Pearson } \\
\text { Correlation }\end{array}$ & $.623^{* *}$ & 1 \\
\hline & Sig. (2-tailed) & .000 & \\
\hline & $\mathrm{N}$ & 100 & 100 \\
\hline
\end{tabular}

**. Correlation is significant at the 0.01 level (2-tailed).

Finally, Table 5 summarizes the results of testing hypotheses as follows:

Table 5 - Summary of test hypotheses

\begin{tabular}{lll}
\hline Final result & Significance & hypotheses \\
\hline rejected & $\begin{array}{l}\text { Without } \\
\text { significant }\end{array}$ & $\begin{array}{l}\text { 1st hypothesis: there is a significant relationship between } \\
\text { the dimensions of organizational structure and corporate } \\
\text { identity in the administration of the province of West } \\
\text { Azerbaijan. }\end{array}$ \\
accepted & significant & $\begin{array}{l}\text { 2nd hypothesis: there is a significant relationship } \\
\text { between corporate responsibility and corporate identity } \\
\text { in the administration of the province of West Azerbaijan. } \\
\text { 3rd hypothesis: there is a significant relationship } \\
\text { between corporate identity and corporate identity in the } \\
\text { administration of the province of West Azerbaijan. } \\
\text { 4th hypothesis: there is a significant relationship } \\
\text { between organizational support and corporate identity in } \\
\text { the administration of the province of West Azerbaijan. }\end{array}$ \\
\hline accepted & significant &
\end{tabular}


International Journal of Security, Privacy and Trust Management (IJSPTM) Vol 3, No 1, February 2014

\section{CONCLUSION}

The study of "organizational space survey of corporate identity in the administration of the province of West Azerbaijan," will examine the relationship between organizational space and organizational identity. In this regard, the relationship between the three criteria proposed by Litwin and Stringer indicators (1968) such as the dimensions of organizational structure; corporate responsibility, corporate identity and organizational support were examined. The relationship between labor productivity managers of corporate identity was also examined.

In this study, four indicators of organizational space and productivity of corporate identity management attention have been addressed. The main question is whether there is a significant relationship between the institutional environment and corporate identity in the administration of the province of West Azerbaijan? Correct answer can be strengthened and enhanced corporate identity in organizations.

Creating an appropriate organizational climate can be very effective in increasing the efficiency. The findings of this study alignment, and coordinate with the results of those investigations such as canvas, Gardner (1988); Litwin and Stringer (1968), Wuhan (1983), Abdullah (1992) and Nazem $(1999,2001,2004)$. There is a significant relationship between the dimensions of organizational structure and corporate identity in the administration of the province of West Azerbaijan. There is also a significant relationship between corporate responsibility and corporate identity in the administration of the province of West Azerbaijan.

There is a significant relationship between the productivity of office managers and corporate identity in Western Azerbaijan. There is a significant relationship between organizational support and corporate identity in the administration of the province of West Azerbaijan. Limitation of the study is that there was a lack of proper co-director of research by the researcher in completed questionnaires. In this study, four indicators were considered among indicators of institutional space, which can be found due to other factors in the other results.

It is suggested that support the organizational identity by applying efficient management mechanisms and the creation of appropriate institutional environment, particularly given the responsibility of operating efficiency, in order to betterment the organizational identity in West Azerbaijan. Competent manager and head professional in this field are expected to use effective variables, such as organizational health, organizational climate, culture, position control, etc to achieve the near and far objectives of agencies. They should use the principles of management and human relations, organizational, creative and productive workforce efficiency and effectiveness of the organization and attempt to reinforce human resources and enhance the organization. 
International Journal of Security, Privacy and Trust Management (IJSPTM) Vol 3, No 1, February 2014

\section{REFERENCES}

[1] Abdullah, Mahlok, (1992) "Organizational culture/ the key to excellence, Malaysian Success Stories. Better quality of work life through Productivity", APO. Abstract, PhD, Virginia Commonwealth University.

[2] Baumgardner, John Elizabeth, (1988), "perceptions of nursing and faculty and administrators about organizational climate and its effect on research productivity in baccalaureate and higher degree programs of nursing education", Dissertation abstract, PHD, the University of Akron.

[3] Boulden, George, P. (1992). "Productivity linked to Profitability the basis for improve worklife. Betler quality of work life throug productivity", (Asian productivity Organizations).

[4] Farhangi, Ali Akbar \& Safarzadeh, Hosein, (2008) "research methods in the human science (with a view on the dissertation writing)" Pyam-e-Pouya publishing, Tehran, second edition.

[5] French, Wendell L. (1986) "Human resources management". Houghton- mifflin company.

[6] Kashani, Majid \& Khanyfar, Hussein, (2011) "The impact of organizational culture on productivity", thesis. School year of 90-91.

[7] Moghimi, Mohammad, (2011) "Organization and Management Research Approach". Termeh Publications, Tehran, 7th Edition.

[10] Nazem, Fattah, (1987), "productivity management (organizational climate and productivity)", Islamic Azad University Research Publications (Roudehen)

[11] Nazem, Fattah, (2001) "study the Relationship between leadership style and organizational climate and productivity of Islamic Azad university managers to provide appropriate management model," $\mathrm{PhD}$ thesis of Department of Management, Science and Research Islamic Azad University.

[13] Nazem, Fattah, (2004) "Study the Relationship between leadership style and organizational climate and productivity management services of petrochemical industry to provide appropriate management model", research project, the National Petrochemical Company of Iran.

[14] Saatchi, Mahmoud \& Kamkari, Kambiz \& Asgarian, Mahnaz, (2011) "Psychological tests", Vireyesh Publications, Tehran, second edition.

[15] Taheri, Shahnam, (2006) "productivity and quality management", Tehran, Aein Publications.

[16] Vaughan, K. M., (1983) "The Relationship of Managers", Education, Training and Experience to Organizational Climate and Productivity. [Dissertation Abstract ,Ed. D. ], Boston University. 